\title{
Microplastics and polycyclic aromatic hydrocarbons (PAHs) in Xiamen coastal areas: Implications for anthropogenic impacts
}

\author{
Guowen Tang a,b, Mengyang Liu ${ }^{\mathrm{a}, \mathrm{b}}$, Qian Zhou ${ }^{\mathrm{e}}$, Haixia He ${ }^{\mathrm{c}}$, Kai Chen ${ }^{\mathrm{c}}$, Haibo Zhang ${ }^{\mathrm{h}}$, Jiahui Hu ${ }^{\mathrm{b}}$, \\ Qinghui Huang ${ }^{\mathrm{f}}$, Yongming Luo ${ }^{\mathrm{e}}$, Hongwei Ke ${ }^{\mathrm{a}, \mathrm{b}}$, Bin Chen ${ }^{\mathrm{c}}$, Xiangrong Xu ${ }^{\mathrm{g}}$, Minggang Cai a,b,c,d,* \\ a State Key Laboratory of Marine Environmental Science, Xiamen University, Xiamen 361102, China \\ b College of Ocean and Earth Sciences, Xiamen University, Xiamen 361102, China \\ c Coastal and Ocean Management Institute, Xiamen University, Xiamen 361102, China \\ d Fujian Provincial Key Laboratory for Coastal Ecology and Environmental Studies, Xiamen University, Xiamen 361102, China \\ e Key Laboratory of Coastal Zone Environmental Processes and Ecological Remediation, Yantai Institute of Coastal Zone Research, Chinese Academy of Sciences, Yantai 264003, China \\ ${ }^{\mathrm{f}}$ Key Laboratory of Yangtze River Water Environment of the Ministry of Education, College of Environmental Science and Engineering, Tongji University, Shanghai 200092, China

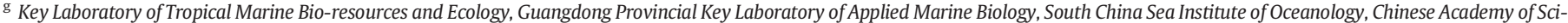 \\ ences, Guangzhou 510301, China \\ ${ }^{\mathrm{h}}$ Key Laboratory of Soil Contamination Bioremediation of Zhejiang Province, Zhejiang AEF University, Hangzhou 311300, China
}

\section{H I G H L I G H T S}

- Microplastics and PAHs were observed in the marine environments in Xiamen coastal areas.

- The abundance of microplastics showed a geographical variety, which was dominant in the Western Harbor.

- Relationships among different types of microplastics and PAHs were derived from the cluster analysis.

- Correlation analysis illustrated the possible influence of human activities on microplastics.

\section{A R T I C L E I N F O}

\section{Article history:}

Received 29 January 2018

Received in revised form 27 March 2018

Accepted 27 March 2018

Available online 10 April 2018

\section{Keywords:}

Microplastics

POPs

Cluster analysis

Correlation analysis

Human activities

Southeast China

\section{G R A P H I C A L A B S T R A C T}

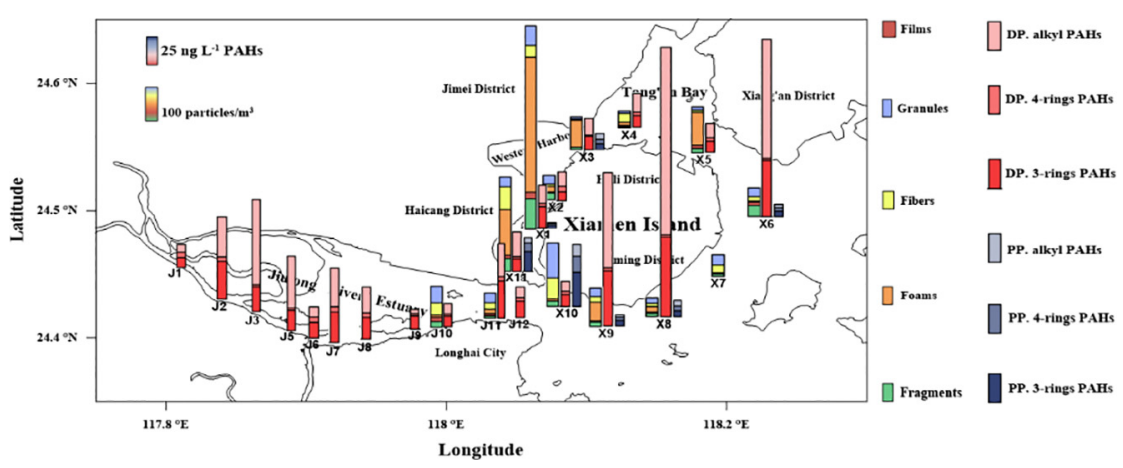

\begin{abstract}
A B S T R A C T
Microplastics and polycyclic aromatic hydrocarbons (PAHs) were investigated to study the influence of human activities and to find their possible relationship on the coastal environments, where the coastal areas around Xiamen are undergoing intensive processes of industrialization and urbanization in the southeast China. The abundance of microplastics in Xiamen coastal areas was 103 to 2017 particles $/ \mathrm{m}^{3}$ in surface seawater and 76 to 333 particles/kg in sediments. Concentrations of dissolved PAHs varied from 18.1 to $248 \mathrm{ng} / \mathrm{L}$ in surface seawater. The abundances of microplastics from the Western Harbor in surface seawater and sediments were higher than those from other areas. Foams were dominated in surface seawater samples, however, no foams were found in sediments samples. The microscope selection and FTIR analysis suggested that polyethylene (PE) and polypropylene (PP) were dominant microplastics. The cluster analysis results demonstrated that fibers and granules had the similar sources, and films had considerably correlation with all types of PAHs (3 or 4-ring PAHs and alkylated PAHs). Plastic film mulch from agriculture practice might be a potential source of microplastics in study areas. Results of our study support that river runoff, watershed area, population and urbanization rate influence
\end{abstract}

\footnotetext{
* Corresponding author at: State Key Laboratory of Marine Environmental Science, Xiamen University, Xiamen 361102, China.

E-mail address: mgcai@xmu.edu.cn. (M. Cai).
} 
the distribution of microplastics in estuarine surface water, and the prevalence of microplastic pollution calls for monitoring microplastics at a national scale.

(c) 2018 Elsevier B.V. All rights reserved.

\section{Introduction}

Plastics have been widely produced and used with enormous demands, and million tons of them finally enter into the oceans (Eubeler et al., 2010; Tosin et al., 2012). Microplastics, normally defined as plastic debris with a diameter $<5 \mathrm{~mm}$, originate from intentional manufacture (primary origins) or the subsequent fragmentation (secondary origins) (Fendall and Sewell, 2009; Wright et al., 2013). A large number of microplastics have been found in the seawater (Cole et al., 2011; Zobkov and Esiukova, 2017), beaches (Claessens et al., 2011; Liebezeit and Dubaish, 2012), and sediments (van Franeker et al., 2011; Van Cauwenberghe et al., 2013; Obbard et al., 2014). It has been proposed that the accumulation of floating plastic debris in different time intervals results from the combined effect of sedimentation, shore deposition, fragmentation and ingestion processes (Peng et al., 2017).

The widespread microplastics in the environment have become a hot spot since they may well exert a physical damage on the marine biota, such as internal abrasions and blockages. Moreover they have the special affinity for organic pollutants (Andrady, 2011; Wright et al., 2013), among which polycyclic aromatic hydrocarbons (PAHs) are one of the most widespread contaminants which have mainly pyrogenic sources. PAHs could pose serious risk to human health due to their toxicity, carcinogenicity and mutagenicity (Cai et al., 2016a). Therefore, microplastics play a role in aquatic ecotoxicology as vectors for these toxic substances, though the bioavailability of these pollutants carried by microplastics has not been studied in detail (Moore, 2008; Hartmann et al., 2017). The coastal or estuarine environments with mass industries and agricultural activities are considered as key areas for contaminants, such as for microplastics and organic pollutants (Browne et al., 2011; Wright et al., 2013). Compared to the beaches, seawater and sediments were the major living environment for the marine biota. Along the coastline in China, the first quantitative study of microplastics was conducted in 2013, and it focused on the seawater near the Yangtze River Estuary (Zhao et al., 2014). Besides, several studies have been reported in recent years focusing on the seawater, sediments in Yangtze River Estuary, Pearl River Estuary, Minjiang River, where massive abundance of microplastics were found (Qiu et al., 2015; Zhao et al., 2015; Peng et al., 2017).

Xiamen is a developing coastal city located in the front of the Jiulong River Estuary, the second largest river in Fujian province, China. As one of the four special economic zones, Xiamen has accomplished remarkable social and economic achievements since the early 1980s. Rapid population growth and intense industrial activities in Xiamen have led to huge pressure on coastal ecosystem stability, which attracts growing attention from the government, the public and academy (Ren et al., 2011; Ma et al., 2016; Huang et al., 2017). In addition, the Xiamen coast receives large amounts of waste from the Jiulong River Basin, where a developed agricultural region is located (Cao et al., 2005; Peng et al., 2013). This further deteriorated local ecological situation. On that account, Xiamen was select as a demonstration plot in East Asia for integrated coastal management since 1994, to explore the way to balance multiple use conflicts from both land and sea, and to control pollution sources (Cai et al., 2016b). The coastal environment situation of Xiamen coast has been the subject of extensive study and government efforts for rehabilitation. Some pollutants and their related ecological influence in Xiamen coast have been reported, such as nutrients (Cai et al., 2016b), heavy metals (Chen et al., 2010), PAHs (Ya et al., 2014), pesticide (Wu et al., 2017) and antibiotics (Zheng et al., 2011). However, there is few information about the microplastics pollution. Therefore, for effective management decision, it is urgent to investigate the microplastics in Xiamen coast and its relationship with human activities. The aims of this study are as follows: 1 ) to investigate the abundance and distribution of microplastics and PAHs in Xiamen coastal areas, including Xiamen Bay and the Jiulong River Estuary. 2) to find their possible relationship by using cluster analysis. 3) to identify the sources of microplastics and see their relationship with human activities.

\section{Materials and methods}

\subsection{Study areas}

Xiamen has an area of about $1700 \mathrm{~km}^{2}$ and a population of near 4 million. It is an important harbor city located on the southeast coast of Fujian Province, China. The study areas can be divided into 3 different parts (Fig. 1), i.e. the Western Harbor (including X1-5 and X11-12), the Open Sea that located at the eastern part of Xiamen Island (including X6-8), and the Jiulong River Estuary (including J1-J12 and X9-10). The Western Harbor is a dumbbell-shaped semi-enclosed bay located at the Western side of Xiamen Island (Cai et al., 2016b). The Jiulong River is the second largest river in Fujian Province, which has a basin area up to $14,700 \mathrm{~km}^{2}$ and supports over 5 million populations. The open sea is located at the eastern side of Xiamen Island, where is significantly affected by the seawater outside.

Since the policy of reform and opening has been implemented for 40 years, Xiamen has become one of the most developed and populous areas in China. Intense economic activities and rapid population growth, however, have led to strong anthropogenic stress on coastal ecosystems. This area receives not only most of domestic sewage (partially untreated) and industrial wastewater from Xiamen coast, but also the agricultural runoff from the Jiulong River Basin that carries great amounts of fertilizers and pesticides.

\subsection{Sampling and pretreatment for microplastics}

\subsubsection{Microplastics in surface seawater}

All the samples were collected in March 2017 in the Western Harbor and the Jiulong River Estuary (Fig.1). Surface seawater samples (X1-11 and J10-11) were collected using a manta trawl ( $1 \mathrm{~m}$ wide $\times 0.5 \mathrm{~m}$ vertical opening, $3 \mathrm{~m}$ long, $0.33 \mathrm{~mm}$ mesh) (Ryan et al., 2009). The net was towed a straight line with the vessel speed being kept at an average of 2 knots for $10 \mathrm{~min}$ (Table S2) and the top $35-50 \mathrm{~cm}$ of the water column was collected. A calibrated flow meter (HYDRO-BIOS, Germany) was attached to the mouth of the net to allow for volume calculation of the water filtered. The contents of the net were then washed into a precleaned glass jar with Milli-Q water, and fixed in 2.5\% formalin for further laboratory processes (Lattin et al., 2004).

In the laboratory, the large debris $(>5 \mathrm{~mm})$ were screened with a $5 \mathrm{~mm}$ steel-wire sieve and discarded. The rest were filtered onto nylon filters (Millipore, $20 \mu \mathrm{m}$ ), and were oxidatively conducted using $30 \% \mathrm{H}_{2} \mathrm{O}_{2}$ (Nuelle et al., 2014). After filtered with nylon filters (20 $\mu \mathrm{m})$, plastic particles were separated via flotation in $\mathrm{NaCl}$ solution (with a density of $1.2 \mathrm{~g} / \mathrm{cm}^{3}$ ) for $24 \mathrm{~h}$, and then the supernatant was collected for further analysis (Hidalgo-Ruz et al., 2012).

\subsubsection{Microplastics in surface sediments}

The samples were collected with a box grab at 8 stations (J1-5, J12, X3 and X12) in April 2017 (Fig. 1). And then all surface sediments samples $(<5 \mathrm{~cm})$ were shoveled with a clean stainless steel spoon and stored 


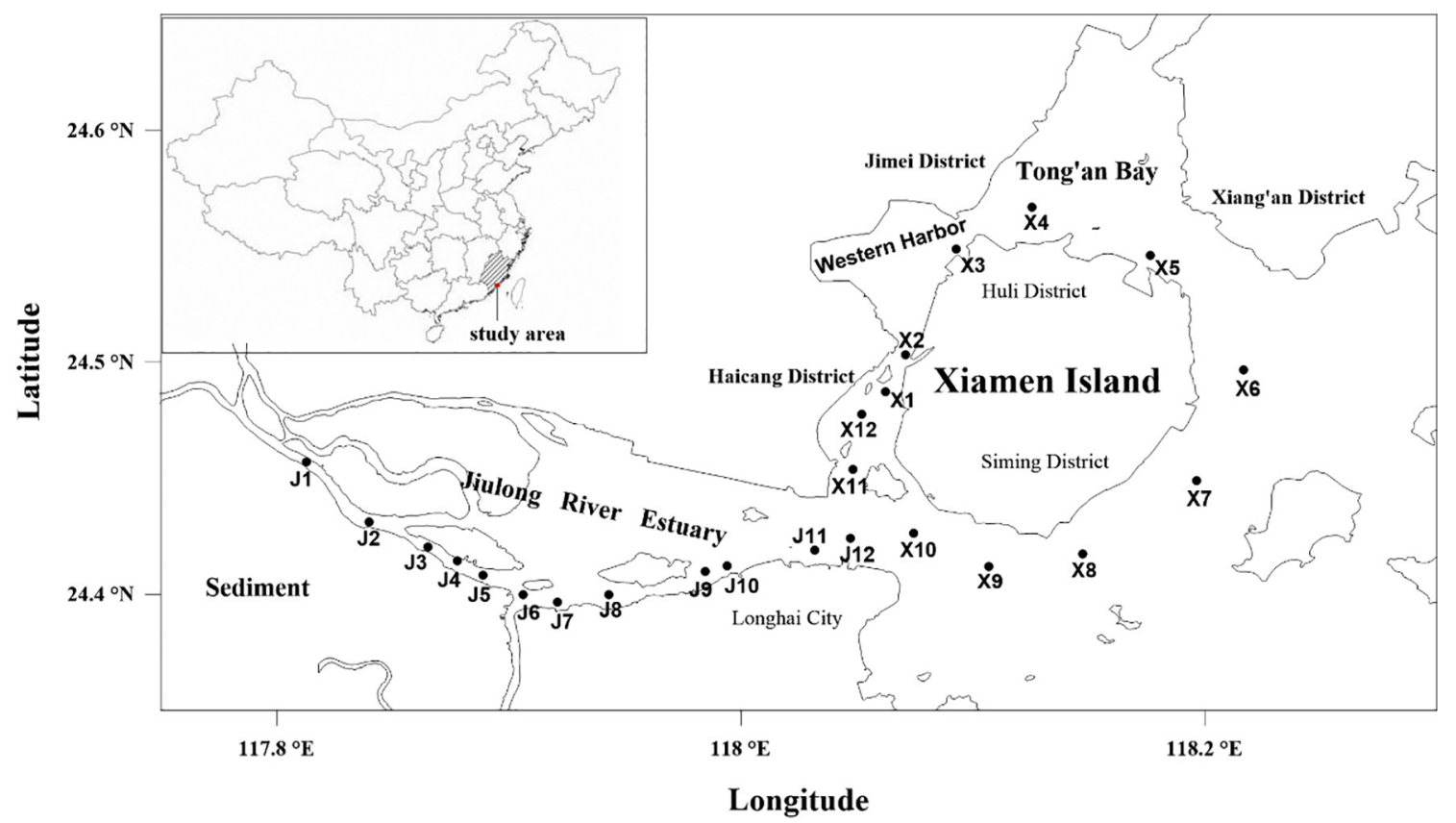

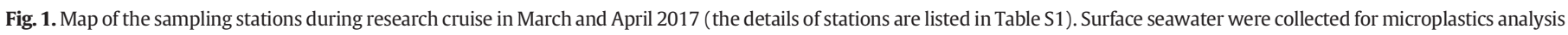

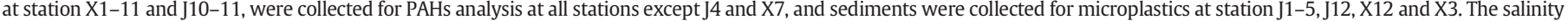
and temperature are shown in the Table S3.

in pre-cleaned aluminum specimen boxes until analysis. The boxes were rinsed with Milli- $Q$ water three times at laboratory before using.

In the laboratory, the samples $(500 \mathrm{~g}$ ) were moved into $2 \mathrm{~L}$ precleaned glass beakers and $500 \mathrm{~mL}$ sodium hexametaphosphate solution $(51 \mathrm{~g} / \mathrm{L})$ were added to disperse the sediments by using an ultrasonic bath (30 min). The treated samples were separated by $\mathrm{NaCl}$ solution (with a density of $1.2 \mathrm{~g} / \mathrm{cm}^{3}$ ) with a stainless steel mesh sieve (330 $\mu \mathrm{m})$, which were assembled on the modified air flow flotation unit (Claessens et al., 2013; Zhu, 2015). $30 \% \mathrm{H}_{2} \mathrm{O}_{2}$ was added to degrade organic matter for about $24 \mathrm{~h}$ (Nuelle et al., 2014). Then, $500 \mathrm{~mL} \mathrm{ZnCl}$ (with a density of $1.5 \mathrm{~g} / \mathrm{cm}^{3}$ ) solution was added to glass beaker for floatation ( $24 \mathrm{~h}$ ) (Liebezeit and Dubaish, 2012). For filtration, it was poured through a nylon filter $(20 \mu \mathrm{m})$ aided by a vacuum pump and then rinsed with Milli-Q water. Finally, the filter paper was stored in a filter paper box before microscopic observation.

\subsubsection{Identification and analysis for microplastics}

The filter membrane was put under a Microscope (ZEISS, Scope A1, Germany) at up to $40 \times$ magnification (Fig. 2) and taken photos using "zigzag" pattern until everywhere had been covered. If the microplastics debris were stuck together, we separated each piece with tweezers.

Microplastics were enumerated and measured by categorizing them on the basis of 5 shapes: fragments, films, foams, fibers and granules. In fact, it should be noted that foams are not a kind of shape. In our study, foams were individually picked out for counting due to their physicochemical property. However, we listed them with the other four shapes together for clear statistics. Color was another visual characteristic we also noted, which was divided into four groups: white, black, transparent and colored. The unit of microplastics abundance was particles per cubic meter (particles $/ \mathrm{m}^{3}$ ) for seawater, and particles per kilogram (particles $/ \mathrm{kg}$ ) for sediments. The particles were alternatively selected to identify the polymers type by using Micro Fourier Transform Infrared Spectrometer (FT-IR) (Thermo Fisher, Nicolet 6700, U.S.A). Highest similarity (at least 70\% similarity for confirmation) in the database were assigned to the microplastics samples (Hidalgo-Ruz et al., 2012).

The detector spectral range was $7600-450 \mathrm{~cm}^{-1}, 16$ scans at a resolution of $4 \mathrm{~cm}^{-1}$ (Detector DTGS). The spectra that we got were processed by MONIC ${ }^{\mathrm{TM}}$ Picta $^{\mathrm{TM}}$ software and compared with the OMNIC polymer spectra library.

\subsection{Sampling and pretreatment for PAHs}

All the surface seawater samples for PAHs were collected at 22 stations (J1-3, J5-12, X1-6 and X8-12) in March and April 2017. 25 L surface seawater samples in the Western Harbor and the Open Sea were collected and filtered over a GF/F filter (Waterman, USA) $(0.70 \mu \mathrm{m}$



Fig. 2. The selected microplastics in surface seawater from Xiamen coastal areas under microscope (40× magnification). 
pore size, $142 \mathrm{~mm}$ diameter) using a filtering system assisted by a peristaltic pump. The filters were collected to analyze the particulate PAHs, and $4 \mathrm{~L}$ of the filtered water for the dissolved PAHs analysis. In the Jiulong River, only $4 \mathrm{~L}$ seawater was filtered over a GF/F filter (Waterman, USA) $(0.70 \mu \mathrm{m}$ pore size, $47 \mathrm{~mm}$ diameter $)$ used for the dissolved phase. The filtrates water sample was spiked with surrogate standards (acenaphthylene-d10, phenanthrene-d 10 , chrysene- $d 12$ and pyrene- $d 12$ ) (AccuStandard, USA), and passed through $\mathrm{C}_{18}$ SPE cartridges (Envi 18, Supelco, USA) (pre-conditioned with $5 \mathrm{~mL}$ of methanol and $5 \mathrm{~mL}$ deionized water) at a flow rate of $6 \mathrm{~mL} \mathrm{~min}{ }^{-1}$.

For dissolved PAHs, the pre-treatment procedure was described in our previous paper in detail (Cai et al., 2016a; Ke et al., 2017). In brief, the targets on SPE cartridges were eluted with $10 \mathrm{~mL}$ of ethyl acetate (SIGMA-ALDRICH, HPLC, USA), with 8-9 g of anhydrous sodium sulfate (pre-combusted) (GB/T9853-2008) on its top to remove the water. For particulate PAHs, the freeze-dried GF/F filters were cut and spiked with surrogate standards, then extracted by acetone/n-hexane $(1: 1, \mathrm{v} / \mathrm{v})$ (SIGMA-ALDRICH, HPLC, USA) in an ultrasonic bath for three times. After being merged, the extracts were concentrated to $1 \mathrm{~mL}$, cleaned by pretreated alumina/silica gel chromatography, and eluted with $10 \mathrm{~mL}$ of dichloromethane/n-hexane $(1: 1, v / v)$ (SIGMA-ALDRICH, HPLC, USA). The eluents for both dissolved and particulate PAHs were solvent-exchanged to n-hexane and concentrated to $1 \mathrm{~mL}$ using a rotary evaporator. After further concentration under nitrogen and addition of internal standard (pyrene- $\mathrm{d}_{10}$ ) (AccuStandard, USA), finally $200 \mu \mathrm{L}$ of mixture was stored at $-4{ }^{\circ} \mathrm{C}$ prior to instrumental analysis. The analysis of 16 USEPA priority PAHs and 4 alkyl-PAHs was using a gas chromatography equipped with mass spectrometry in tandem (GC-MS-MS) (the details of instrument are provided in supplementary materials).

\subsection{Quality assurance and quality control}

For microplastics, procedural blanks were conducted along with the samples. All of the experiment tools were rinsed at least three times with Milli-Q water and then dried before using. Lab coats and gloves were worn to avoid any contamination. Only fibers, no fragments, films, foams and granules, were found in the blanks. The blank values were low and stable, which had an average of one fibers per blank measurement ( 0 to 2 fibers per blank measurement). The fiber abundance reported in this study were corrected for the blanks.

For PAHs, two field blanks and three laboratory blanks were analyzed for PAHs (Table S4). Method detection limits were derived from average field blanks plus three times the standard deviation (Table S4). In addition, four perdeuterated PAHs were added to samples prior to extraction on the expedition, and the average recoveries of acenaphthylene-d10, phenanthrene-d10, chrysene-d12 and pyrlene-d12 were $82 \pm 14,72 \pm 12,62 \pm 15$ and $76 \pm 26 \%$, respectively.

\subsection{Statistical analysis of data}

Cluster analysis was used to identify the environmental behaviors of microplastics and PAHs. Pearson correlation analysis was employed to investigate the relationship between microplastics abundance and various watershed characteristics (e.g., runoff, watershed area, land use) in different drainage basin. All analyses were performed by using SPSS version 22.0 (IBM Corporation).

To analyze the association between microplastics distribution and human activities, we collected related parameters of watershed characteristic and socio-economic development. The references of river runoff and watershed area, population, gross domestic product (GDP) and disposable income (DPI) and land use were listed in Table S7.

\section{Results and discussion}

\subsection{Microplastics and PAHs in surface water}

\subsubsection{Abundance and distribution of microplastics}

Microplastics were observed in seawater at all stations near the Xiamen coastal areas (Fig. 3 and Table S5), and the concentrations ranged from 103.0 to 2071 particles $/ \mathrm{m}^{3}$, with an average of $514.3 \pm 520.0$ particles $/ \mathrm{m}^{3}$. In general, the extent of microplastics was in the lower level compared with those reported in seawater from Yangtze Estuary and Minjiang Estuary in China (Zhao et al., 2015; Zhao et al., 2014) (Fig. S2). Higher abundance of $4137 \pm 2461$ particles $/ \mathrm{m}^{3}$ and $1245 \pm$ 531.5 particles $/ \mathrm{m}^{3}$ respectively were reported in the Yangtze Estuary and Minjiang Estuary. It should be noted that different approaches were used in those studies, thus the variation of results should be considered when compared with other studies. Except for the difference in methodology, other possible explanation of the lower abundance in the Xiamen coastal were human population-density (Browne et al., 2011) and rainy season (Ivar do Sul and Costa, 2013; Williams and Simmons, 1999). Firstly, Browne et al. (2011) found that there were more microplastics in densely populated areas with a significant relationship between its abundance and human population-density. Shanghai was one of the most populated cities in China, whose population was significantly higher than that in Xiamen and Fuzhou by up to 1 orders of magnitude. As a consequence, the abundance of microplastics in the Xiamen coastal and Minjiang Estuary were much lower than those in Yangtze River Estuary. Secondly, higher river flows in the rainy season from March to April might result in the decrease of microplastics in surface seawater. The weather of the day before sampling in March was rainy. Consequently, a significant amount of plastic debris retained in the estuary might have been washed out to the sea.

In different areas (the Western Harbor, the Jiulong River Estuary and the Open Sea), we found that samples from the Western Harbor had the highest value with an average of $695.8 \pm 735.0$ particles $/ \mathrm{m}^{3}$, whereas samples from the Eastern Sea and the Jiulong River Estuary had the an average of $252.0 \pm 58.90$ particles $/ \mathrm{m}^{3}$ and $438.8 \pm 190.7$ particles $/ \mathrm{m}^{3}$, respectively (Fig. 3 ). The abundance in surface seawater was highest in the Western Harbor between the Xiamen Island and the Haicang District, where human activities such as industrial production, bathing beach and resident areas were frequent. Geographical condition might be another reason for the highest abundance. The western harbor was a semi-enclosed bay, which had the special hydrodynamic conditions with weak seawater exchange. As a consequence, it was difficult for the floating particles to flow outside this area (Claessens et al., 2011). The lowest abundance was encountered in the open sea, and the low abundance was possibly on account of the seawater flow to the outside, which would dilute the microplastics that come from human activities at eastern Xiamen Island.

\subsubsection{Shape and color of microplastics}

Different shapes of microplastics were observed from the samples including fragments, films, foams, fibers and granules, and each sample area varied significantly with the others (Fig. 4A). The percentage of foams was highest in the Western Harbor (60.0\%). However, foams were almost the lowest in the open sea (8.0\%) and the Jiulong River Estuary $(16.4 \%)$, whereas granules showed an opposite trend $(10.7 \%$ for the Western Harbor, $43.9 \%$ and $46.6 \%$ for the Eastern Sea and the Jiulong River Estuary, respectively). Based on the high value of foams observed, it was possibly that at least a portion of the microplastics in the Western Harbor could be related to the point source emissions (Schilling and Zessner, 2011), such as industrial areas (Pruter, 1987; Gregory, 1991) and packaging (Derraik, 2002).

Different colors of microplastics were observed from the samples including white, black, transparent and colored (Fig. 4C). White particles were the most abundant (50\%), which were dominated by the foams, followed by colored particles that account for 30\%. Black and 


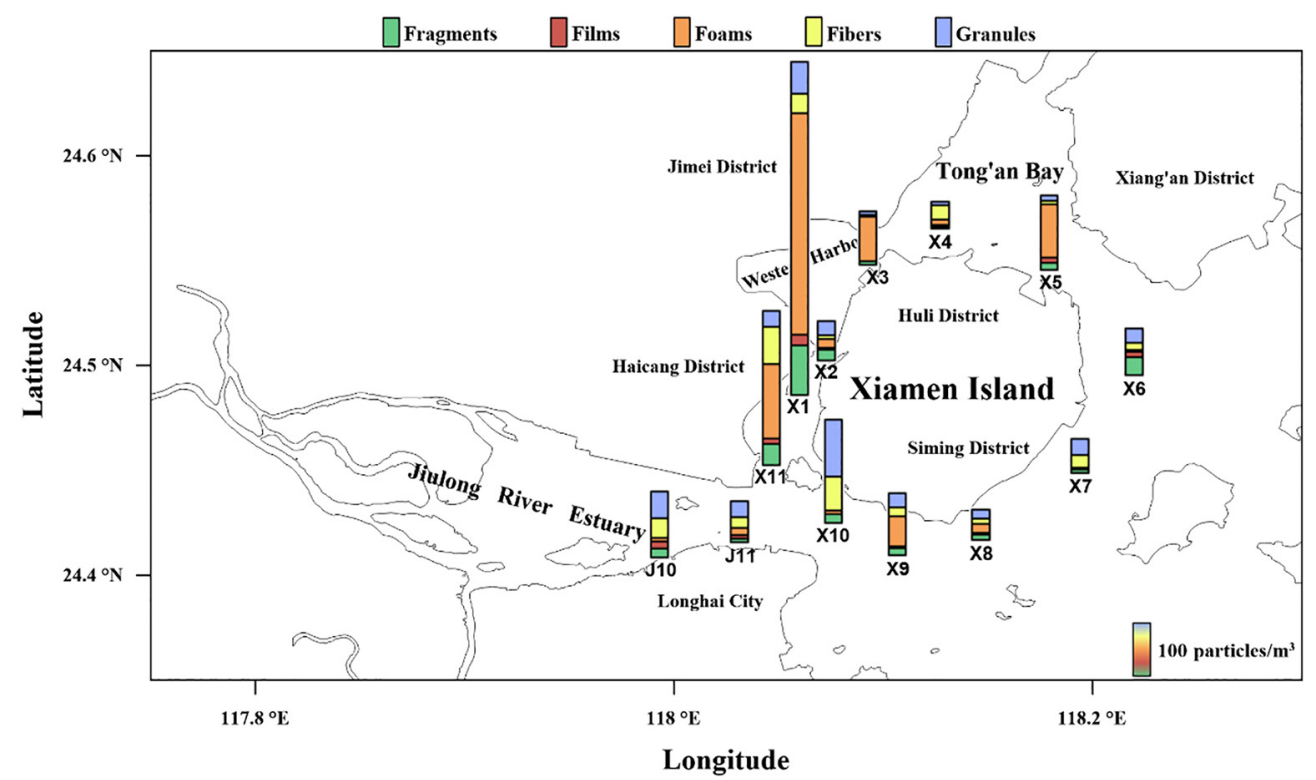

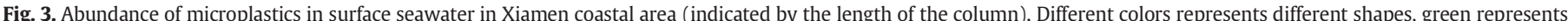


reader is referred to the web version of this article.)
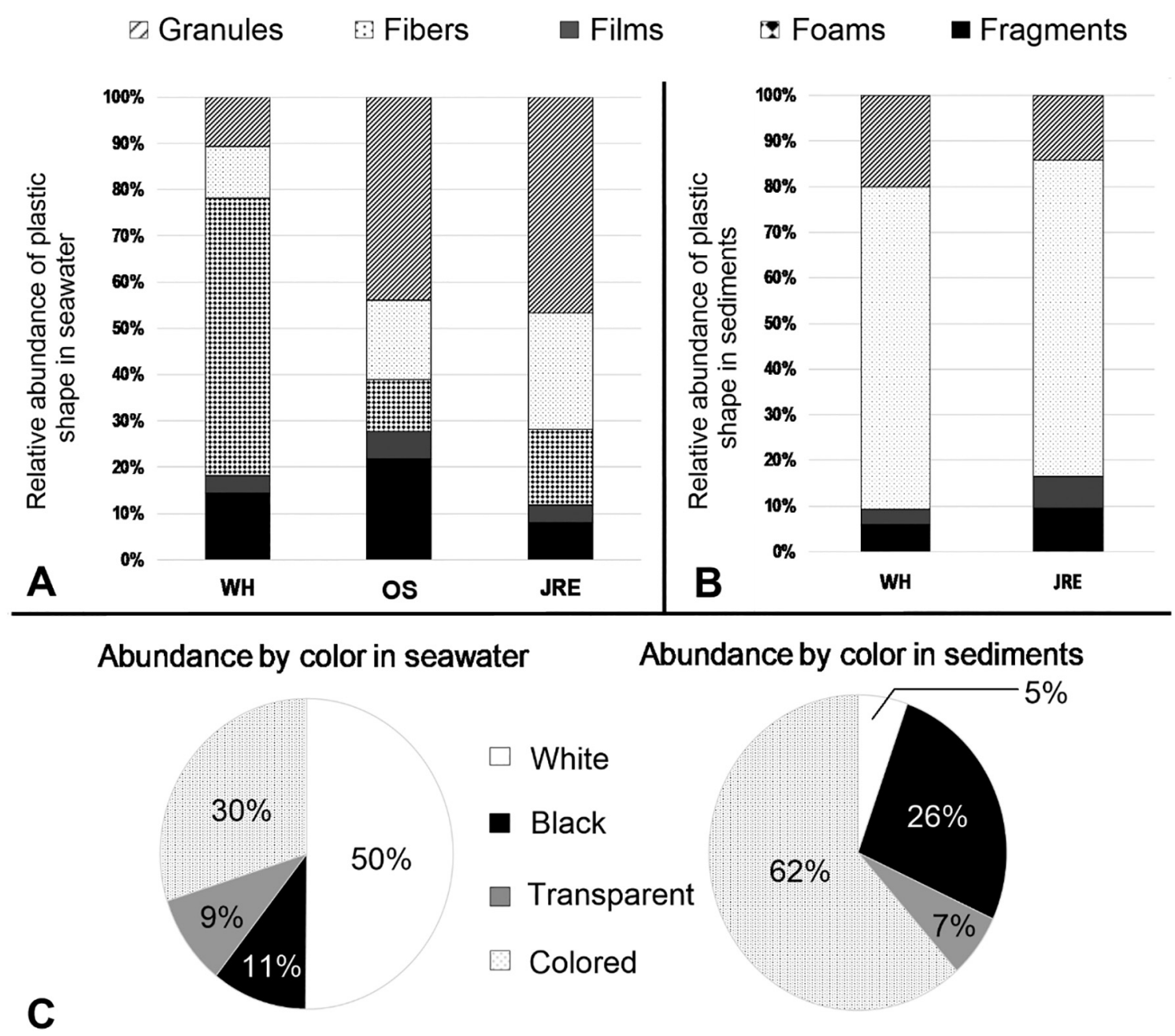

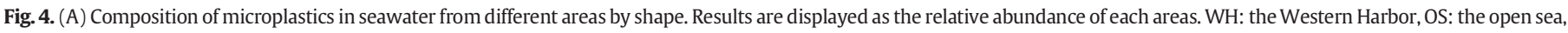

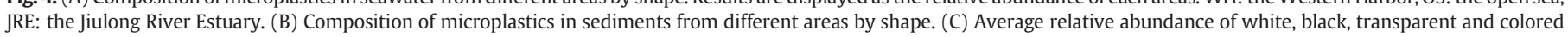
particles found in seawater and sediments respectively. 
transparent particles had almost the same proportion, contributing $11 \%$ and $9 \%$, respectively (Fig. $4 \mathrm{C}$ ).

\subsubsection{Identification of microplastics}

Six different polymer types were identified as microplastics in seawater samples (Table S8), including polyethylene (PE), polypropylene (PP), polystyrene (PS), polyester (PES), Polyether urethane (PU), and cellophane. All foams were identified as PS. It should be noted the presence of cellophane was not a type of microplastics. However, Peng et al. (2017) found that a part of rayon fibers in sediments of Yangtze Estuary was identified as cellophane. Rayon was a synthetic textile fiber made from cellulose (Jarmin, 1994), which differentiated them from bright color of cellophane. Because this material could not be distinguished from other microplastics during selection, and their low abundance may not affect the result significantly, cellophane was enlisted in our study.

Of all selected particles, PE and PP contributed 50.4\% and $28.7 \%$ respectively, followed by cellophane (7.8\%) (Table S8). The remaining proportion of particles were PES (5.2\%), PU (4.3\%) and PS (3.5\%). There were several possible reasons that might explain the composition of materials. Firstly, the frequent use of PE and PP in industry, which were the most popular plastics in our daily life, gave rise to their large abundance (Klein et al., 2015). Secondly, the low specific densities of PE, PP and flowing PS allow for the existence in seawater rather than bottom. The low abundance of other polymers in seawater system was possibly caused by their less frequent usage and higher density.

\subsubsection{Abundance and compositions of PAHs in water and SPM}

The total PAHs ( $\sum_{13} \mathrm{PAHs}$ ) here included the sum of 3-ring and 4ring parent compounds, as well as alkyl-PAHs (Table S9-12). The dissolved $\sum_{13}$ PAHs varied from 18.13 to $247.8 \mathrm{ng} / \mathrm{L}$ (mean $61.56 \mathrm{ng} / \mathrm{L}$ ), whereas the range of dissolved $\sum_{9} \mathrm{PAHs}$ ( 3 - and 4-ring parent PAHs) was from 12.66 to $75.32 \mathrm{ng} / \mathrm{L}$ (mean $25.86 \mathrm{ng} / \mathrm{L}$ ). The 3-, 4-ring and alkly-PAHs accounted for $41.49 \%, 8.57 \%$ and $49.94 \%$ of the total PAHs, respectively. It was showed that 3-ring and alkyl-PAHs were the most abundant PAHs in the surface water. The levels of PAHs in this study were higher than those in the Western Taiwan Strait (Wu et al., 2011) and Minjiang River Estuary (Zhang et al., 2004), but were comparable to those in Pearl River Estuary (Luo et al., 2008) and the Daliao River Estuary (Mohamad et al., 2011). It seemed that the concentrations of PAHs decreased gradually in recent years compared to previous researches in the same place (Maskaoui et al., 2000; Wu et al., 2017; Ya et al., 2014).
As for the spatial distribution, the abundance of $\sum_{13}$ PAHs in the open sea was higher than that in the Western Harbor and the Jiulong River Estuary (Fig. 5), which might be attributed to frequent maritime transportation. However, high abundance detected at Station J2, J3, J5 within the Jiulong River Estuary might reflect the potential PAHs input from sewage discharges.

The abundance of $\sum_{13} \mathrm{PAHs}$ in particulate phase ranged from 6.16 to $57.93 \mathrm{ng} / \mathrm{L}$ (274.53-2038.9 ng/g), with a mean abundance of $19.63 \mathrm{ng} / \mathrm{L}$ (or $1044.7 \mathrm{ng} / \mathrm{g}$ ). While the particulate $\sum_{9} \mathrm{PAHs}$ ranging from 4.98 to $46.82 \mathrm{ng} / \mathrm{L}$ (or $221.39-1706.3 \mathrm{ng} / \mathrm{g}$ ) with a mean of $15.38 \mathrm{ng} / \mathrm{L}$ (or $813.53 \mathrm{ng} / \mathrm{g}$ ). These levels were less than those in Daliao River Estuary (Mohamad et al., 2011), but were comparable to the levels in the Pearl River Estuary (Luo et al., 2006). The highest abundance was found at station X10, which was even higher than the dissolved phase. This was just consistent with the highest abundance of SPM in this station. In terms of composition pattern of PAHs in particulate phase, the 3ring PAHs were predominant in all SPM samples, ranging from $39.68 \%$ to $58.03 \%$ (with an average of $49.26 \%$ ) of $\sum_{13}$ PAHs. The relative content of alkyl-PAHs (23.29\%) in particulate phase was lower than that in dissolved phase. In contrast, 4-ring PAHs was higher than in dissolved phase, and each percentage of them (FluA, Pyr, BaA, Chr) were similar in all selected stations, which suggested that the adsorption of 4-ring PAHs on SPM tended to be saturated.

\subsubsection{Sources analysis of PAHs}

In this research, PAHs isomer pairs ratios, such as Ant / (Ant + Phen), Flu / (Flu + Pyr), BaA / $(\mathrm{BaA}+\mathrm{Chr})$ and MP/P, were used as chemical tracers to reveal possible sources of PAHs (Fig. S1). Ant / (Ant + phen) ratios over 0.10 and $<0.10$ suggested a pyrogenic source and petrogenic source, respectively. Flu / (Flu + Pyr) ratios $<0.40$ indicated petrogenic source, $0.40-0.50$ indicated petroleum combustion, and $>0.50$ indicated grass, wood, coal combustion. Besides, BaA / (BaA $+\mathrm{Chr})<0.20$ meant petrogenic sources, $>0.35$ meant pyrogenic sources, and $0.20-0.35$ was usually taken as an indicator of mixed source (Yunker et al., 2002). What's more, MP/P ratio $<1$ implied that phenanthrene was derived from pyrogenic processes, and 2-6 implied fossilfuel sources (Prahl and Carpenter, 1983).

Fig. S1 showed the plots those isomer pairs for each samples. The results suggested that combustion sources of PAHs might contribute to the major PAHs burden in this area. The Ant / (Ant + Phen) ratios were $>0.10$ and the MP/P ratios were $<1$ for all samples, suggesting a pyrogenic source of PAHs. As for the particulate phase, the BaA / (BaA

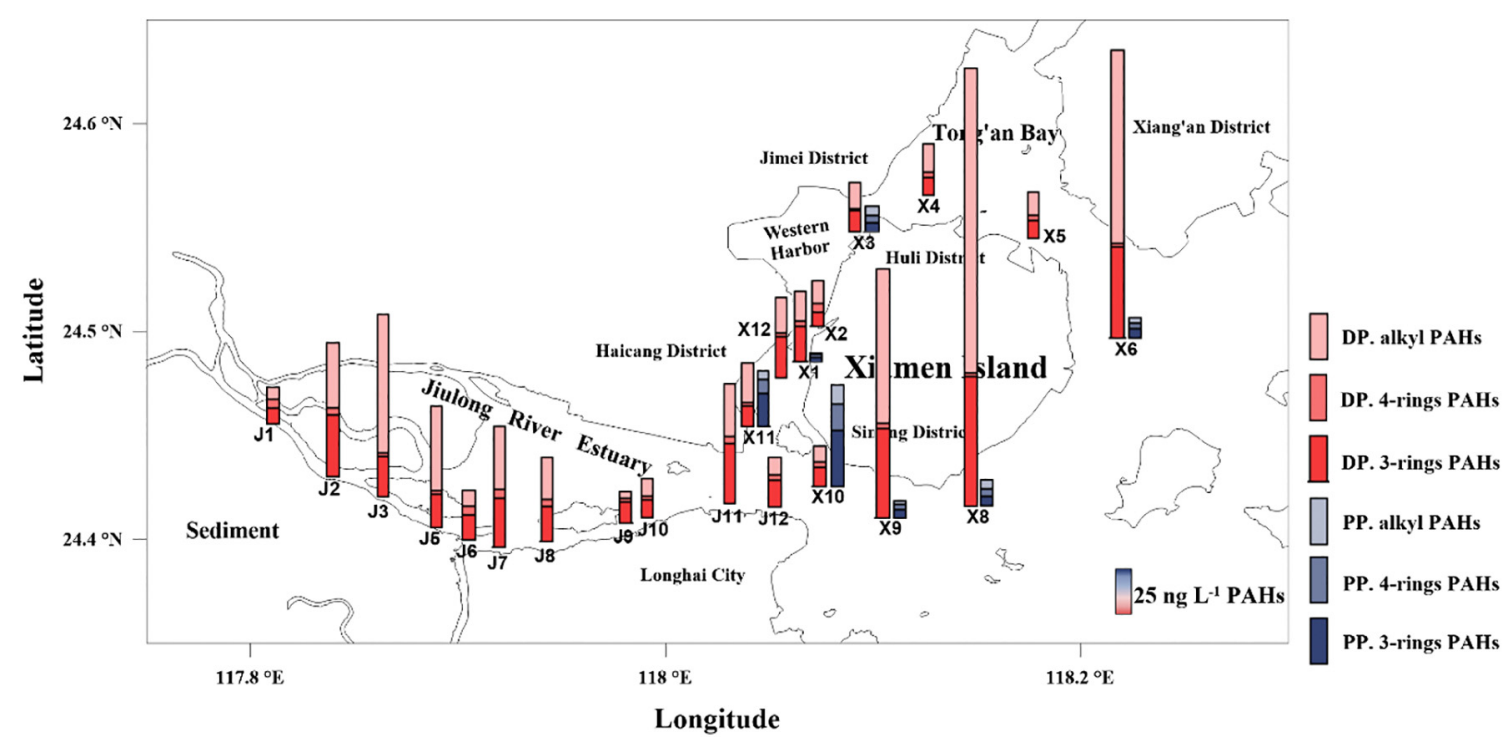

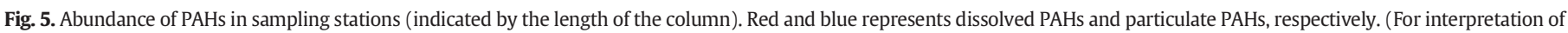
the references to color in this figure legend, the reader is referred to the web version of this article.) 
$+\mathrm{Chr}$ ) ratios over 0.35 and the Flu / (Flu + Pyr) ratios between 0.4 and 0.5 at all sites indicated a pyrogenic source, particularly petroleum combustion. But for the dissolved phase, the Flu / (Flu + Pyr) were $>0.5$ at most sites, which implied grass, wood and coal combustion source. Whereas the $\mathrm{BaA} /(\mathrm{BaA}+\mathrm{Chr})$ ratios showed mixed petroleum and combustion-derived sources in the dissolved phase.

\subsection{Microplastics in surface sediments}

\subsubsection{Abundance and distribution of microplastics}

The number of microplastics found in sediments samples of 8 stations in the Jiulong River Estuary and the Western Harbor was presented in Fig. 5 and Table S6, respectively. The abundance of sediments samples varied from 76 to 333 particles per kilogram (particles $/ \mathrm{kg}$ w.w.). The average microplastics abundance in all stations was 181 particles $/ \mathrm{kg}$. Compared with the number of sediments from Belgian coast, where the abundance was 390 particles $/ \mathrm{kg}$ (Claessens et al., 2011) (Fig. S3), the abundance in our study areas showed a lower level. In addition, it had a much lower abundance than Kachelotplate Island and the beach in Hainan, China(Liebezeit and Dubaish, 2012; Qiu et al., 2015), which was up to 49,600 particles/kg and 6872 particles/ $\mathrm{kg}$ to 8714 particles/kg, respectively. According to the comparison with other studies, it could be seen that the abundance of microplastics in this study was at a lower level. Notably, the differences in experimental methods should be taken into account when we the compared difference of the abundance of microplastics reported in this study with other studies.

Significant difference can be found from abundance between the Western Harbor and the Jiulong River Estuary stations (Fig. 6). Sediments from the Western Harbor had the higher number with an average of $269.3 \pm 80.5$ particles $/ \mathrm{kg}$, with Jiulong River Estuary exhibiting an average of $128.0 \pm 60.9$ particles $/ \mathrm{m}^{3}$. It was possibly because of the river input from the Jiulong River. The fact that abundance decreased along the flow direction in the Jiulong River Estuary stations can also explain the difference between two areas. Furthermore, Nor and Obbard (2014) also reported that the lowest microplastics abundance was associated with low levels of human activities. As the areas around sample stations in the Jiulong River Estuary were agricultural region, the directly discharge from human activities was negligible.

\subsubsection{Shape and color of microplastics}

What was different from the seawater samples is that none of the sediment samples contained foams. The other four major types of particles (based on numbers) were fibers (70.0\%) and granules (17.5\%), which were found at all sampling locations, as well as films and fragments account for $5.0 \%$ and $7.5 \%$, respectively. The percentage of shapes had almost the same proportion in the Western Harbor and the Jiulong River Estuary (Fig. 4B). This indicated a possible microplastics flux from the Jiulong River Estuary to the Western Harbor. Fibrous microplastics seems to be most abundant in the marine environment, which was consistent with other findings (Wright et al., 2013). The higher proportion of fibers in sediments suggested that the microplastics were possibly derived from wastewater because of clothes washing (Browne et al., 2011). In addition, Heavy marine traffic and fishery activities was also deemed to be an important source of fibers (Browne et al., 2011).

Different from the color composition in surface seawater, colored fibers were dominant at the sediments samples. Black particles contributed to averaged $26 \%$ of all microplastics. Transparent and white particles account for $7 \%$ and $5 \%$, respectively (Fig. 4C).

\subsubsection{Identification of microplastics}

Four different polymer types were identified as microplastics in sediments samples, including polypropylene (PP), polyester (PES), Poly (propylene: ethylene) and cellophane. Of all selected particles, PP was the most abundant polymer in sediments samples. However, the fact that PP was the most popular plastics in our daily life could not independently explain their existence logically on account that the density of PP was only $0.92-0.96 \mathrm{~g} / \mathrm{cm}^{3}$. The presence of relatively buoyant microplastics in the sediments may suggest the existence of physical and/or biological processes forcing buoyant microplastics to sink to the bottom of the areas (Frere et al., 2017). And the low abundance of other polymers in sediments system was possibly caused by their high density and less frequent usage.

\subsection{Classification of different types of microplastics and PAHs in surface seawater by cluster analysis (CA)}

Based on the result of microplastics and PAHs in surface seawater, cluster analysis (CA) was used to further classify the different types of contaminants (fragments, films, foams, fibers, granules, 3-rings PAHs,






referred to the web version of this article.) 
4-rings PAHs and alkylated PAHs) into different groups and to identify their correlations with each other. CA produced a dendrogram where the selected contaminants were divided into three clusters at Dlink/ Dmax $<50 \%$ (Fig. 7). The cluster 1 was only characterized with foams, which was coincident with the abovementioned analysis (3.1.2) where high abundance in the western harbor could be related to point source emissions, such as industrialized areas and packaging. Cluster 2 was characterized by fibers and granules, and it suggested that both the two types of microplastics may have the similar origins. For example, Browne et al. (2011) found that a large proportion of microplastic fibers found in the marine environment may be derived from sewage due to washing of clothes. While granules come from certain types of hand cleaners and cosmetic preparations (Claessens et al., 2011), which were also dominant at sewage. Browne et al. (2011) also found that fishing gear was also deemed as an important source of fibers. However, our result showed that fishing activities were not the major source of fibers in Xiamen coastal regions. Cluster 3 could be further divided into two parts, and films showed considerably correlation with all types of PAHs (3-rings PAHs, 4-rings PAHs, and alkylated PAHs). From our speculation, films had higher surface area than the other particles, which was conducive to adsorb PAHs. As we know, PE films were usually used to adsorb PAHs in passive sampling method (Booij et al., 2003), which was very consistent with our work. However, the specific mechanism should be the focus of future research.

\subsection{Relationship between microplastics abundance and human activities}

China is the largest producer and user of plastics in the world, and it may contribute the maximum proportion of waste plastic into the ocean around the world (Jambeck et al., 2015). Different levels of economic growth, urbanization, resource endowment, etc. in Chinese different areas generate apparently diversified microplastics abundance in the coastal environment. Unfortunately, the studies about microplastics pollution and available data of microplastics abundance in coastal area of China are both very limited. Here, we used the published reports by Zhao et al. $(2014,2015)$ with this study to discuss the possible relationship between microplastics abundance and anthropogenic activities, and to identify the potential factors for microplastics distribution in estuaries of our study areas (Table 1 ).

As was shown in Table 2, microplastics abundance in southeast China estuarine has positive correlation with river runoff $(r=0.988, p$

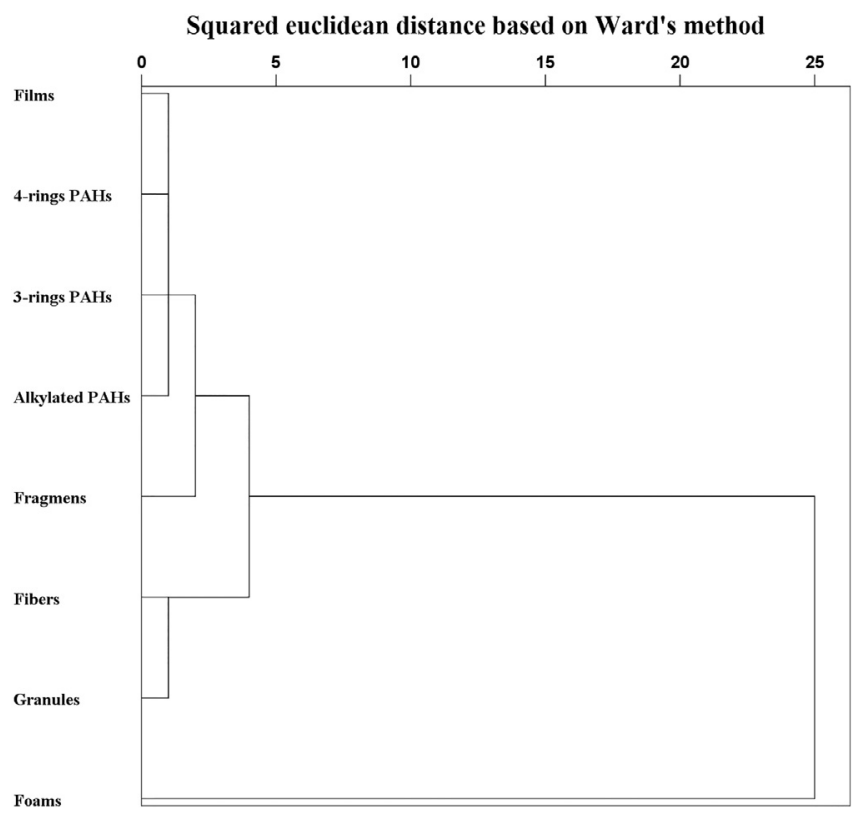

Fig. 7. Dendrogram of the microplastics and PAHs in surface seawater.
Table 1

Characteristics of watershed proximate to estuary surface water sampled for microplastics abundance in southeast China. The references of these data were listed in Table S5.

\begin{tabular}{|c|c|c|c|c|c|}
\hline Characteristics & $\begin{array}{l}\text { Jiulong } \\
\text { River }\end{array}$ & $\begin{array}{l}\text { Ou } \\
\text { River }^{\mathrm{a}}\end{array}$ & $\begin{array}{l}\text { Min } \\
\text { River }^{\mathrm{a}}\end{array}$ & $\begin{array}{l}\text { Jiao } \\
\text { River }^{\text {a }}\end{array}$ & $\begin{array}{l}\text { Yangtze } \\
\text { River }^{\mathrm{b}}{ }^{\mathrm{c}}\end{array}$ \\
\hline $\begin{array}{l}\text { Microplastics abundance } \\
\quad \text { (item } / \mathrm{m}^{3} \text { ) }\end{array}$ & 514 & 680 & 1246 & 956 & 4137 \\
\hline River runoff ( $\mathrm{km}^{3} /$ year $)$ & 14.06 & 20.20 & 62.37 & 5.17 & 881 \\
\hline Watershed area $\left(\mathrm{km}^{2}\right)$ & 14,741 & 18,028 & 60,992 & 6603 & 420,237 \\
\hline Population (million) & 9.11 & 6.95 & 16.58 & 4.53 & 234.78 \\
\hline Population density $\left(\mathrm{km}^{-2}\right)$ & 618 & 385 & 272 & 687 & 559 \\
\hline Urbanization rate $(\%)$ & 71.6 & 64.1 & 59.4 & 58.1 & 62.9 \\
\hline GDP per capita (RMB) ${ }^{d}$ & 78,167 & 54,180 & 54,693 & 46,288 & 67,406 \\
\hline DPI per capita $(\mathrm{RMB})^{\mathrm{d}}$ & 31,087 & 30,585 & 21,304 & 30,950 & 25,862 \\
\hline Farmland (\%) & 18.35 & 20.37 & 19.94 & 30.23 & 29.46 \\
\hline Forest (\%) & 72.85 & 67.44 & 71.82 & 47.45 & 63.06 \\
\hline Water area (\%) & 3.11 & 4.84 & 2.44 & 9.13 & 3.26 \\
\hline Construction land (\%) & 4.67 & 4.25 & 4.57 & 8.42 & 1.41 \\
\hline Barren land (\%) & 0.19 & 3.08 & 1.23 & 4.77 & 2.81 \\
\hline
\end{tabular}

a Microplastics abundance from (Zhao et al., 2015).

b Microplastics abundance from (Zhao et al., 2014).

c Since upper Yangtze River is wild and untraversed, the values of socio-economic parameters and land use only include mid-lower reach, where starts at Yibin City, Sichuan Province.

d In view of comparability, the values of the Jiulong River in 2017 are adjusted to constant price in 2013. RMB means Chinese monetary unit.

$=0.001)$, watershed area $(r=0.991, p=0.001)$, total population $(r$ $=0.986, p=0.002)$ and urbanization rate $(r=0.984, p=0.002)$. It is not surprising that larger area and more population will lead to more waste plastics emission, and larger runoff can transport more microplastics debris from drainage to estuary. Studies in other aquatic ecosystems also support that higher urbanized or industrial areas generate more waste plastics. For example, based on the results in four estuaries of the Chesapeake Bay, Yonkos et al. (2014) observed greater concentrations of microplastics in more densely urban areas. Yangtze River estuary even has the highest concentration of microplastics in the world (Lebreton et al., 2017), because of its enormous watershed area and populations. Moreover, the defective waste management system promotes the waste plastic entering into the environment and finally reaching coastal area (Jambeck et al., 2015). It is noted that the population density has less influence on microplastics abundance.

A preliminary analysis was conduct, which was connected with the relationship between watershed economic level (GDP per capita and DPI per capita) and estuarine microplastics pollution of China, since some water quality indices have been frequently reported, such as nutrient (Chen et al., 2018) and dissolved oxygen (Wong and Lewis, 2013). The results of GDP per capita $(r=-0.415, p=0.487)$ and DPI per capita $(r=-0.192, p=0.757)$ offer a rough negative relationship without statistical significance. Part of the reason may be that the prevent awareness of microplastics pollution is not yet developed with the economic growth, so that plastic is still widely used in China (Qiu

Table 2

Pearson correlation of microplastics abundance with socio-economic and land use characteristics.

\begin{tabular}{lll}
\hline Characteristics & $r$ & $p$ \\
\hline River runoff $\left(\mathrm{km}^{3} / \mathrm{year}\right)$ & 0.988 & $\mathbf{0 . 0 0 1}$ \\
Watershed area $\left(\mathrm{km}^{2}\right)$ & 0.991 & $\mathbf{0 . 0 0 1}$ \\
Population (million) & 0.986 & $\mathbf{0 . 0 0 2}$ \\
Population density $\left(\mathrm{km}^{-2}\right)$ & 0.107 & 0.864 \\
Urbanization rate (\%) & 0.984 & $\mathbf{0 . 0 0 2}$ \\
GDP per capita (RMB) & -0.415 & 0.487 \\
DPI per capita (RMB) & -0.192 & 0.757 \\
Farmland (\%) & 0.604 & 0.280 \\
Forest (\%) & -0.114 & 0.855 \\
Water area (\%) & -0.258 & 0.675 \\
Construction land (\%) & -0.688 & 0.199 \\
Barren land (\%) & 0.162 & 0.795 \\
\hline
\end{tabular}

Pairs with $p$ values below 0.01 (bold) are statistically significant. 
et al., 2015). In addition, there is no incentive for people to use alternatives because of the accessible, durable and low price of plastic production (Derraik, 2002).

An interesting relationship in our study was that farmland $(r=$ $0.604, p=0.280$ ) was positively correlated with microplastics, while construction land $(r=-0.688, p=0.199)$ was on the contrary, despite lack of statistically significance. On the one hand, plastic film mulch plays an important role in Chinese agriculture due to soil warming and moisture conservation effects. Nevertheless, its residual level reaches $50-260 \mathrm{~km} / \mathrm{hm}^{2}$ in farmland based on a long-term investigation since it was hard to be recycled (Liu et al., 2014). On the other hand, more land in construction use generally means lower farmland rate, less plastic use and less residual in the environment, especially in these watersheds. Our study hints that agriculture plastic film mulch could be a significant source of plastic waste in China. On the contrary, Yonkos et al. (2014) found that more land in agriculture or forest uses generally generates less plastic waste in the US. It demonstrates that there was uncertainty in the relationship between microplastics source and land use.

\section{Conclusion}

Microplastics were found in all surface seawater and sediments stations. The abundance of microplastics in Xiamen coastal areas was 103 to 2017 particles $/ \mathrm{m}^{3}$ in surface seawater and 76 to 333 particles $/ \mathrm{kg}$ in sediments. The results indicated that the polluted level in surface seawater and sediments in Xiamen coastal areas was in the middle degree from all over the world. The concentrations of dissolved PAHs varied from 18.13 to $247.75 \mathrm{ng} / \mathrm{L}$ in surface seawater. Foams were dominated in surface seawater samples, however, no foams were found in sediments samples because of their low density. Microscope selection and FTIR analysis confirmed the presence of plastics in the samples and the majorities were PE and PP. The cluster analysis demonstrated that fibers and granules had the similar sources, and films had considerably correlation with all types of PAHs (3-rings PAHs, 4-rings PAHs and alkylated PAHs). Results of our study supported that river runoff, watershed area, population and urbanization rate influenced the distribution of microplastics in estuary surface water. Plastic film mulch from agriculture practice might be a potential source of microplastics in study areas.

\section{Acknowledgement}

Thanks were given to the crew of R/V Haiyang II. Financial support for this study was granted by the National Natural Science Foundation of China (NSFC) (91228202 J1210050, 40776040 and 41576180), the Natural Science Foundation of Fujian Province, China (2012J05078, 2014J06014), Senior Project of Big Science Instrument Office, Institute of Oceanology, Chinese Academy of Sciences (NO-KEXUE2016G01, KEXUE2017G09), and Xiamen University Training Program of Innovation and Entrepreneurship for Undergraduates (2016X0619, 2016X0624). We were especially thankful to Dr. Jun Wang, Ms. Jun Ye, Mr. Weimin Wang and Mr. Sadique Rayhan for their help of sampling, and Dr. Peng Huang for his assistance with data processing. We were also grateful to our reviewers for their comments and language improvements on the research.

\section{Appendix A. Supplementary data}

Supplementary data to this article can be found online at https://doi. org/10.1016/j.scitotenv.2018.03.336.

\section{References}

Andrady, A.L., 2011. Microplastics in the marine environment. Mar. Pollut. Bull. 62, 1596-1605.
Booij, K., Hoedemaker, J.R., Bakker, J.F., 2003. Dissolved PCBs, PAHs, and HCB in pore waters and overlying waters of contaminated harbor sediments. Environ. Sci. Technol. 37 (18), 4213-4220

Browne, M.A., Crump, P., Niven, S.J., Teuten, E., Tonkin, A., Galloway, T., et al., 2011. Accumulation of microplastic on shorelines woldwide: sources and sinks. Environ. Sci. Technol. 45, 9175-9179.

Cai, M., Liu, M.Y., Hong, Q.Q., Lin, J., Huang, P., Hong, J.J., et al., 2016a. Fate of polycyclic aromatic hydrocarbons in seawater from the Western Pacific to the Southern Ocean $\left(17.5^{\circ} \mathrm{N}\right.$ to $\left.69.2^{\circ} \mathrm{S}\right)$ and their inventories on the Antarctic shelf. Environ. Sci. Technol. 50, 9161-9168

Cai, M., Liu, Y., Chen, K., Huang, D., Yang, S., 2016b. Quantitative analysis of anthropogenic influences on coastal water-a new perspective. Ecol. Indic. 67, 673 (2016b). (71: 608-608).

Cao, W.Z., Hong, H.S., Yue, S.P., 2005. Modelling agricultural nitrogen contributions to the Jiulong River estuary and coastal water. Glob. Planet. Chang. 47, 111-121.

Chen, C., Lu, Y., Hong, J., Ye, M., Wang, Y., Lu, H., 2010. Metal and metalloid contaminant availability in Yundang Lagoon sediments, Xiamen Bay, China, after 20 years continuous rehabilitation. J. Hazard. Mater. 175, 1048-1055.

Chen, K., Liu, Y., Huang, D., Ke, H., Chen, H., Zhang, S., et al., 2018. Anthropogenic activities and coastal environmental quality: a regional quantitative analysis in southeast China with management implications. Environ. Sci. Pollut. Res. Int. 25, 3093-3107.

Claessens, M., De Meester, S., Van Landuyt, L., De Clerck, K., Janssen, C.R., 2011. Occurrence and distribution of microplastics in marine sediments along the Belgian coast. Mar. Pollut. Bull. 62, 2199-2204.

Claessens, M., Van Cauwenberghe, L., Vandegehuchte, M.B., Janssen, C.R., 2013. New techniques for the detection of microplastics in sediments and field collected organisms. Mar. Pollut. Bull. 70, 227-233.

Cole, M., Lindeque, P., Halsband, C., Galloway, T.S., 2011. Microplastics as contaminants in the marine environment: a review. Mar. Pollut. Bull. 62, 2588-2597.

Derraik, J.G.B., 2002. The pollution of the marine environment by plastic debris: a review. Mar. Pollut. Bull. 44, 842-852.

Eubeler, J.P., Bernhard, M., Knepper, T.P., 2010. Environmental biodegradation of synthetic polymers II. Biodegradation of different polymer groups. TrAC Trends Anal. Chem. 29, 84-100.

Fendall, L.S., Sewell, M.A., 2009. Contributing to marine pollution by washing your face: microplastics in facial cleansers. Mar. Pollut. Bull. 58, 1225-1228.

Frere, L., Paul-Pont, I., Rinnert, E., Petton, S., Jaffre, J., Bihannic, I., et al., 2017. Influence of environmental and anthropogenic factors on the composition, concentration and spatial distribution of microplastics: a case study of the Bay of Brest (Brittany, France). Environ. Pollut. 225, 211-222.

Gregory, M.R., 1991. The hazards of persistent marine pollution- drift plastics and conservation islands. J. R. Soc. N. Z. 21, 83-100.

Hartmann, N.B., Rist, S., Bodin, J., Jensen, L.H.S., Schmidt, S.N., Mayer, P., et al., 2017. Microplastics as vectors for environmental contaminants: exploring sorption, desorption, and transfer to biota. Integr. Environ. Assess. Manag. 13, 488-493.

Hidalgo-Ruz, V., Gutow, L., Thompson, R.C., Thiel, M., 2012. Microplastics in the marine environment: a review of the methods used for identification and quantification. Environ. Sci. Technol. 46, 3060-3075.

Huang, H., Chen, B., Ma, Z., Liu, Z., Zheng, S., Yu, W., et al., 2017. Assessing the ecological security of the estuary in view of the ecological services- a case study of the Xiamen Estuary. Ocean Coast. Manag. 137, 12-23.

Ivar do Sul, J.A., Costa, M.F., 2013. Plastic pollution risks in an estuarine conservation unit. J. Coast. Res. 48-53.

Jambeck, J.R., Geyer, R., Wilcox, C., Siegler, T.R., Perryman, M., Andrady, A., et al., 2015. Plastic waste inputs from land into the ocean. Science 347, 768-771.

Jarmin, R.S., 1994. Learning by doing and competition in the early rayon industry. RAND J. Econ. 25, 441-454.

Ke, H.W., Chen, M., Liu, M.Y., Chen, M., Duan, M.S., Huang, P., et al., 2017. Fate of polycyclic aromatic hydrocarbons from the North Pacific to the Arctic: field measurements and fugacity model simulation. Chemosphere 184, 916-923.

Klein, S., Worch, E., Knepper, T.P., 2015. Occurrence and spatial distribution of microplastics in river shore sediments of the Rhine-main area in Germany. Environ. Sci. Technol. 49, 6070-6076.

Lattin, G.L., Moore, C.J., Zellers, A.F., Moore, S.L., Weisberg, S.B., 2004. A comparison of neustonic plastic and zooplankton at different depths near the southern California shore. Mar. Pollut. Bull. 49, 291-294.

Lebreton, L.C.M., van der Zwet, J., Damsteeg, J.W., Slat, B., Andrady, A., Reisser, J., 2017. River plastic emissions to the world's oceans. Nat. Commun. 8, 15611.

Liebezeit, G., Dubaish, F., 2012. Microplastics in Beaches of the East Frisian Islands Spiekeroog and Kachelotplate. Bull. Environ. Contam. Toxicol. 89, 213-217.

Liu, E.K., He, W.Q., Yan, C.R., 2014. 'White revolution' to 'white pollution'-agricultural plastic film mulch in China. Environ. Res. Lett. 9

Luo, X.J., Chen, S.J., Mai, B.X., Yang, Q.S., Sheng, G.Y., Fu, J.M., 2006. Polycyclic aromatic hydrocarbons in suspended particulate matter and sediments from the Pearl River Estuary and adjacent coastal areas, China. Environ. Pollut. 139, 9-20.

Luo, X.J., Mai, B.X., Yang, Q.S., Chen, S.J., Zeng, E.Y., 2008. Distribution and partition of polycyclic aromatic hydrocarbon in surface water of the Pearl River Estuary, South China. Environ. Monit. Assess. 145, 427-436.

Ma, D.Q., Fang, Q.H., Liao, S.H., 2016. Applying the Ocean Health Index framework to the city level: a case study of Xiamen, China. Ecol. Indic. 66, 281-290.

Maskaoui, K., Hong, H.-s., Zhang, Z.-1., Chen, W.-q., Zhou, J.-l., 2000. Distribution and composition of PAHs in surface waters, porewater and sediments from Xiamen Western Bay. Chin. J. Oceanol. Limnol. 19, 73-80.

Mohamad, I., Hwejeh, I., Nasser, M., 2011. Distribution of polycyclic aromatic hydrocarbons (PAHs) in marine shore sediments of Alkaber Aljanuby River Estuary, Boundary River (Syria-Lebanon). Fresenius Environ. Bull. 20, 2624-2631. 
Moore, C.J., 2008. Synthetic polymers in the marine environment: a rapidly increasing, long-term threat. Environ. Res. 108, 131-139.

Nor, N.H., Obbard, J.P., 2014. Microplastics in Singapore's coastal mangrove ecosystems. Mar. Pollut. Bull. 79, 278-283.

Nuelle, M.-T., Dekiff, J.H., Remy, D., Fries, E., 2014. A new analytical approach for monitoring microplastics in marine sediments. Environ. Pollut. 184, 161-169.

Obbard, R.W., Sadri, S., Wong, Y.Q., Khitun, A.A., Baker, I., Thompson, R.C., 2014. Global warming releases microplastic legacy frozen in Arctic Sea ice. Earth's Future 2, 315-320.

Peng, B., Chen, N., Lin, H., Hong, H., 2013. Empirical appraisal of the Jiulong River Watershed Management Program. Ocean Coast. Manag. 81, 77-89.

Peng, G., Zhu, B., Yang, D., Su, L., Shi, H., Li, D., 2017. Microplastics in sediments of the Changjiang Estuary, China. Environ. Pollut. 225, 283-290.

Prahl, F.G., Carpenter, R., 1983. Polycyclic aromatic hydrocarbon (PAH)-phase associations in Washington coastal sediment. Geochim. Cosmochim. Acta 47, 1013-1023.

Pruter, A.T., 1987. Sources, quantities and distribution of persistent plastics in the marine environment. Mar. Pollut. Bull. 18, 305-310.

Qiu, Q.X., Peng, J.P., Yu, X.B., Chen, F.C.Z., Wang, J.D., Dong, F.Q., 2015. Occurrence of microplastics in the coastal marine environment: first observation on sediment of China. Mar. Pollut. Bull. 98, 274-280.

Ren, Y., Wei, X., Wei, X., Pan, J., Xie, P., Song, X., et al., 2011. Relationship between vegetation carbon storage and urbanization: a case study of Xiamen, China. For. Ecol. Manag. 261, 1214-1223.

Ryan, P.G., Moore, C.J., van Franeker, J.A., Moloney, C.L., 2009. Monitoring the abundance of plastic debris in the marine environment. Philos. Trans. R. Soc. B 364, 1999-2012.

Schilling, K., Zessner, M., 2011. Foam in the aquatic environment. Water Res. 45 4355-4366.

Tosin, M., Weber, M., Siotto, M., Lott, C., Degli Innocenti, F., 2012. Laboratory test methods to determine the degradation of plastics in marine environmental conditions. Front. Microbiol. 3.

Van Cauwenberghe, L., Vanreusel, A., Mees, J., Janssen, C.R., 2013. Microplastic pollution in deep-sea sediments. Environ. Pollut. 182, 495-499.

van Franeker, J.A., Blaize, C., Danielsen, J., Fairclough, K., Gollan, J., Guse, N., et al., 2011. Monitoring plastic ingestion by the northern fulmar Fulmarus glacialis in the North Sea. Environ. Pollut. 159, 2609-2615.

Williams, A.T., Simmons, S.L., 1999. Sources of riverine litter: the River Taff, South Wales, UK. Water Air Soil Pollut. 112, 197-216.
Wong, Y.L., Lewis, L., 2013. The disappearing Environmental Kuznets Curve: a study of water quality in the Lower Mekong Basin (LMB). J. Environ. Manag. 131, 415-425.

Wright, S.L., Thompson, R.C., Galloway, T.S., 2013. The physical impacts of microplastics on marine organisms: a review. Environ. Pollut. 178, 483-492.

Wu, Y.-L., Wang, X.-H., Li, Y.-Y., Hong, H.-S., 2011. Occurrence of polycyclic aromatic hydrocarbons (PAHs) in seawater from the Western Taiwan Strait, China. Mar. Pollut. Bull. 63, 459-463.

Wu, Y., Wang, X., Li, Y., Ya, M., Luo, H., Hong, H., 2017. Polybrominated diphenyl ethers, organochlorine pesticides, and polycyclic aromatic hydrocarbons in water from the Jiulong River Estuary, China: levels, distributions, influencing factors, and risk assessment. Environ. Sci. Pollut. Res. 24, 8933-8945.

Ya, M.-L., Wang, X.-H., Wu, Y.-L., Ye, C.-X., Li, Y.-Y., 2014. Enrichment and partitioning of polycyclic aromatic hydrocarbons in the sea surface microlayer and subsurface water along the coast of Xiamen Island, China. Mar. Pollut. Bull. 78, 110-117.

Yonkos, L.T., Friedel, E.A., Perez-Reyes, A.C., Ghosal, S., Arthur, C.D., 2014. Microplastics in Four Estuarine Rivers in the Chesapeake Bay, USA. Environ. Sci. Technol. 48, 14195-14202.

Yunker, M.B., Macdonald, R.W., Vingarzan, R., Mitchell, R.H., Goyette, D., Sylvestre, S. 2002. PAHs in the Fraser River basin: a critical appraisal of PAH ratios as indicators of PAH source and composition. Org. Geochem. 33, 489-515.

Zhang, Z.L., Hong, H.S., Zhou, J.L., Yu, G., 2004. Phase association of polycyclic aromatic hydrocarbons in the Minjiang River Estuary, China. Sci. Total Environ. 323, 71-86.

Zhao, S., Zhu, L., Wang, T., Li, D., 2014. Suspended microplastics in the surface water of the Yangtze Estuary System, China: first observations on occurrence, distribution. Mar. Pollut. Bull. 86, 562-568.

Zhao, S., Zhu, L., Li, D., 2015. Microplastic in three urban estuaries, China. Environ. Pollut 206, 597-604.

Zheng, S., Qiu, X., Chen, B., Yu, X., Liu, Z., Zhong, G., et al., 2011. Antibiotics pollution in the Jiulong River estuary: source, distribution and bacterial resistance. Chemosphere 84 1677-1685.

Zhu, X., 2015. Optimization of elutriation device for filtration of microplastic particles from sediment. Mar. Pollut. Bull. 92, 69-72.

Zobkov, M., Esiukova, E., 2017. Microplastics in Baltic bottom sediments: quantification procedures and first results. Mar. Pollut. Bull. 114, 724-732. 